\title{
Membrane Science and Membrane Engineering: a Successful Story
}

\author{
Enrico Drioli, ${ }^{*, a, b, c, d}$ Elena Tocci, ${ }^{a}$ and Francesca Macedonio ${ }^{a, b}$ \\ ${ }^{a}$ National Research Council-Institute on Membrane Technology, ITM-CNR, clo University of Calabria, \\ Via P. Bucci Cubo 17/C, 87036 Arcavacata di Rende (CS), Italy \\ ${ }^{b}$ Department of Environmental and Chemical Engineering, University of Calabria, Via P. Bucci Cubo 42/A, \\ 87036 Arcavacata di Rende (CS), Italy \\ ${ }^{c}$ Hanyang University, WCU Energy Engineering Department, Room 917 9th Floor FTC BIdg., \\ 17 Haengdang-dong, Seongdong-gu, Seoul 133-791, South Korea \\ ${ }^{d}$ Center of Excellence in Desalination Technology, King Abdulaziz University, Jeddah, Saudi Arabia
}

Email: e.drioli@itm.cnr.it (E. D.)

\begin{abstract}
Membrane engineering is one of the disciplines most involved in the technological innovations necessary to face the problems characterizing the world today and in future such as water shortage, raw material depletion, and energy consumption. Membrane operations contribute to solving these problems, and the potentialities of membrane operations have been widely recognized in the last few years. In this work, an overview of membrane applications and their perspectives in the field of membrane materials, membrane modelling and water treatment will be analyzed. The scope of this study is to show how membranes, membrane operations and their integration could contribute to the redesign of membrane engineering in the logic of the process intensification strategy.
\end{abstract}

Keywords membrane engineering, membrane materials, membrane science

\section{Introduction}

The last century has been characterized by a huge resource-intensive industrial development, particularly in some Asian countries, spurred by the growth in the global population level, by a significant elongation of life expectation, and by an overall increase in the standard and quality of life. However, the positive aspects realized from the industrial development have to be combined with the emergence of related problems such as water stress, environmental pollution, and increase of $\mathrm{CO}_{2}$ emissions into the atmosphere. These negative aspects have been related to the lack of innovations and introduction of new strategies capable of both controlling and minimizing the relatively obvious negative aspects of industrial development worldwide. Today, the evolution of industrial development requires the transition from an industrial system based on quantity to one based on quality. Human capital is increasingly becoming the driving force behind this socio-economic transformation. The challenge of sustainable growth also relies on the use of advanced technologies and processes. Indeed, process engineering is one of the disciplines most involved in the technological innovations necessary to face the new problems characterizing the world today and in the future as well. Recently, the logic of process intensification has been suggested as the best process engineering answer to the situation. It consists of innovative equipment, design, and process development methods that are expected to bring substantial improvements in chemical and any other manufacturing and processing, such as decreasing production costs, equipment size, energy consumption, waste generation, improving remote control, information fluxes, and process flexibility (Figure 1).

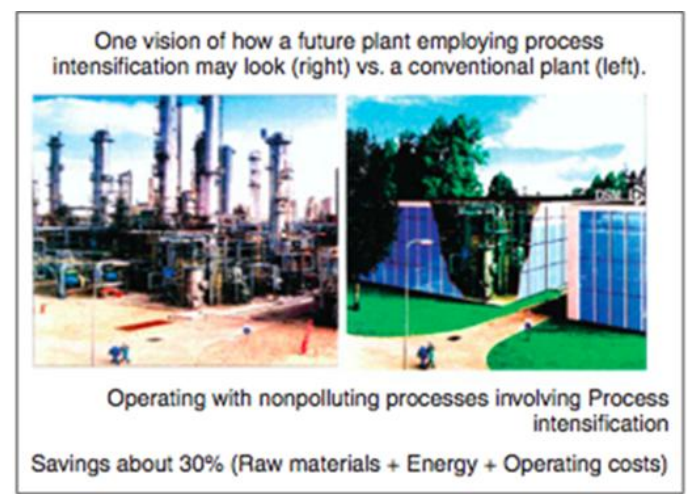

Figure 1 Process intensification strategy. Modified with permission from Jean-Claude Charpentier, Modern Chemical Engineering in the Framework of Globalization, Sustainability, and Technical Innovation, Ind. Eng. Chem. Res. Vol. 46, No. 11, 2007. Copyright @ 2007, American Chemical Society.

The potential benefits of process intensification for the process industry are significant in terms of energy savings, reduction of $\mathrm{CO}_{2}$ emissions and enhanced cost competitiveness. They will significantly impact each sector of the process industry in one way or another. In 2009, the first attempt to define the fundamentals of process intensification was undertaken by Van Gerven and Stankiewicz, and four generic principles/objectives of PI have been defined. ${ }^{[1]}$ Modern membrane engineering is an important case of process intensification and various membrane technologies are recognized as BestAvailable Technologies (BATs) (Figure 2). ${ }^{[2]}$ 


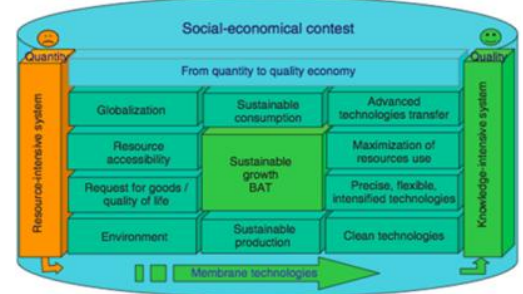

Figure 2 Current social-economic and technological contest driving the transition toward and knowledge-intensive system to guarantee sustainable growth. Reprinted with permission from Preface and Introduction to Comprehensive Membrane Science and Engineering, Second Edition, 2017, Pages xv-xix. Copyright@2017, Elsevier.

Membrane operations, with their intrinsic characteristics of efficiency and operational simplicity, high selectivity and permeability for the transport of specific components, compatibility between different membrane operations in integrated systems, low energetic requirement, good stability under operating conditions and environmental compatibility, easy control and scale-up, and large operational flexibility, represent an interesting answer for the rationalization of chemical and any other industrial productions. Many membrane operations are practically based on the same hardware (materials), only differing in their software (methods). The traditional membrane separation operations (reverse osmosis (RO), microfiltration (MF), ultrafiltration (UF), and nanofiltration (NF), electrodialysis, pervaporation, etc.), already largely used in many different applications, are today conducted with new membrane systems such as catalytic membrane reactors and membrane contactors. At present, redesigning important industrial production cycles by combining various membrane operations suitable for separation and conversion units, thus realizing highly integrated membrane processes, is an attractive opportunity because of the synergic effects that can be attained.

In various fields, membrane operations are already dominant technologies. Interesting examples are in seawater desalination (Figure 3), in wastewater treatment and reuse, and in artificial organs.

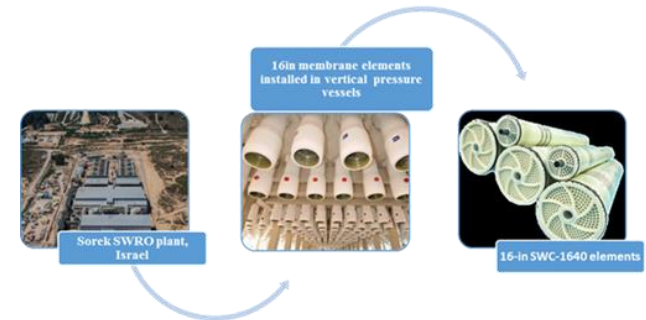

Figure 3 The world's largest and cheapest reverse-osmosis desalination plant is up and running in Israel and is called Sorek. It provides $20 \%$ of the water consumed by Israel households. It produces 627,000 cubic meters of water daily.

Large part of the membrane operations realized today at the industrial level are based on the approach of biomimicry, i.e., seeking sustainable solutions by emulating nature's time-tested patterns and strategies. ${ }^{[3]} \mathrm{A}$ major part of biological systems is, in fact, well represented by membranes, which operate molecular separations, chemical transformation, molecular recognition, energy, mass and information transfer, etc. (Figure 4). Although some functions have been transferred at the industrial level with success, we have many outstanding challenges to reproduce the complexity and efficiency of the biological membranes.

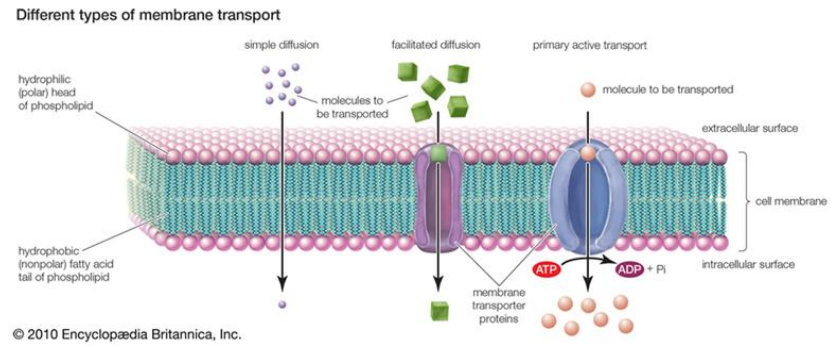

Figure 4 Biological membrane functions. Encyclopædia Britannica, Inc. Freely accessible from https://www.britannica. com/science/membrane-biology/media/374264/114973

This requires strong efforts in spreading the available knowledge in membrane engineering to the public and for educating the younger generations more and more in the fundamental and applications of these disciplines. Indeed, an update of the traditional Academic Educational Systems is essential. For instance, the presence of Membrane Engineering courses in the Education Curricula of Chemistry and Chemical Engineering in most part of Universities Worldwide is very limited. Therefore, Higher Education, particularly in Engineering, requires new instruments and new approaches, in particular, multi-disciplinarity and global vision. A wide global cooperation between the Educational and Research Institutes will create synergies for the research and the development of innovative technologies. ${ }^{[4]}$

In this work, we will show how membranes, membrane operations and their integration could contribute to the redesign of membrane engineering in the logic of the process intensification strategy.

\section{Materials and Membranes}

The realization of new membranes with controlled morphology is an important topic for membrane technology development also in nanotechnology applications that can further extend their fields of application. The ability to control pore sizes in the membrane preparation process can be used not only for highly selective separation process but also in chemical conversion, supplying extremely ordered and confined geometries for chemical reactions. Nanoscale control of membrane architecture, by some well-known techniques such as lasers and etching, previously used in microelectronic fabrications, have been already used to create membrane structures at nano-scale level. Track etch membrane are systems, in which the pore size, shape and density can be varied in a controllable mode so that the transport and retention characteristics of the membrane can be modulated.

This technology is one of the bases of an increasing number of membrane media for industrial application. ${ }^{[5]}$ Electrospun nano-fiber membranes show very interesting results, too. ${ }^{[6-9]}$

In electrospinning process, the fibers formed show very high porosity, excellent hydrophobicity or hydrophilicity (for applications that do not favor hydrophobicity such as for biomedical applications, for reducing protein adhesion, etc.), very good interconnectivity and very high surface to volume ratio making them interesting candidates, for example, for desalination applications. Electrospinning can be performed with polymer solution or melt and the properties of the mat can be tuned by changing the process parameters, material used and the applied post treatment step. Due to the possibility to use polymer melt, instead of solution, electrospinning provides opportunities to make the membranes with vast variety of polymers. Different functional materials can be incorporated into the nano-fibers during or after their spinning thus incorporating 
multi functionality into the fibers.

Another interesting frontier in membrane technology is self-assembling. ${ }^{[10-13]}$ Self-assembly process consists in the regular assembly of small molecular entities into larger supramolecular structures, exhibiting new functions that cannot be exhibited by the isolated units. The interaction between subunits is generally due to non-covalent bonds, such as hydrogen bonds, Van der Waals interactions and electrostatic forces. Recently, stable macroscopic membranes formed by the self-assembly of amphiphilic peptides, i.e., peptides with alternating hydrophobic and hydrophilic residues have been patented. ${ }^{[14]}$ These membranes, stable in aqueous solution, serum, and ethanol, are highly resistant to heat, non-cytotoxic, alkaline and acidic $\mathrm{pH}$, chemical denaturants, and proteolytic digestion. Some of their potential uses also include biomaterial applications such as slow-diffusion drug delivery system and artificial skin.

Nanotubes are even new systems that are gaining increasing attention in membrane field. ${ }^{[15-17]}$ The nanometricscale size and the hollow, cylindrical shape of nanotubes suggest that they may be used as membranes with pores on the order of $1-100 \mathrm{~nm}$. Membranes made of precisely sized nanotubes, prepared via the template method, had also great potential for filtration and separation processes. Gold nanotube membranes have been successfully synthesized using a template-based electroless plating technique. ${ }^{[18]}$ The enantiomer selector human serum albumin, immobilized on the inner surface of the nanotubes through a reactive thiol, works as a bionanodevice for chiral resolution. ${ }^{[19]}$

Graphene is another interesting material with several applications due to its very high strength to weight ratio. ${ }^{[2,21]}$ In addition to its use in various fields (foldable electronics, biological engineering, composite materials, energy storage), the new research has shown that it exhibits amazing selective permeability towards various components. ${ }^{[22,23]}$ For example, a sub-micron thin graphene oxide membrane can retain all gases and liquids through the membrane except water molecules. The separation of water from organic mixtures has been demonstrated excellently by these membranes. ${ }^{[24]}$ Similarly, graphene membranes can selectively permeate some metals ions present into a solution containing different types of ions. ${ }^{[25,26]}$ Graphene membrane with thickness near to $1 \mathrm{~nm}$ has shown excellent selectivity towards various gases. ${ }^{[27]}$ Due to these facts combined with their high strength, it is possible to reduce the thickness of the graphene-based membranes tremendously.

Biomimic membranes like aquaporin have shown a great potential for desalination applications due to their high permeability and selectivity towards water molecules. ${ }^{[28]}$ Under the right conditions, aquaporin membranes form the water channels allowing the passage of only water molecules and exclusion of all ions.

Two-dimensional (2D) materials ${ }^{[29]}$ of atomic thickness represent the next generation membrane materials with extraordinarily high permeability. ${ }^{[30-33]} 2 \mathrm{D}$ membranes with welldefined transport channels and ultra-low thicknesses have demonstrated exceptional performance for liquid and gas separation applications. The unique atomic thickness of the membrane offers ultra-low resistance to mass transport. The potential materials for 2D membranes include zeolites, mixed-organic frameworks, graphene, molybdenum disulfide, etc. For example, metal-organic framework (MOF)-functionalized alumina membranes have been designed for seawater desalination via vacuum membrane distillation (VMD) by Zuo et al. ${ }^{[34]}$ The resultant membranes possess the intrinsic advantages of alumina supports (such as high stability and high water permeability) and have also the hydrophobic surface formed by MOF func- tionalization. $\mathrm{N}$-Butylamine modified graphene oxide (GO-NBA) has been added in poly(vinylidene fluoride) (PVDF) flat-sheet and hollow fiber membranes for enhancing the mechanical properties and wetting resistance of pristine PVDF membranes to be used in membrane distillation desalination. ${ }^{[35]}$

The current main challenges for the commercial scale implementation of 2D membranes include limited available techniques for exfoliating the high aspect ratio and intact nanoporous monolayers from bulk crystals, drilling of the pores with required characteristics (uniform, high-density, large-area, subnanosized) in membrane matrix and scaling up of these atomic scale membranes into real scale separation devices. ${ }^{[36]}$

\section{Modelling of Membranes and Membrane Opera- tions}

A good understanding of the materials properties and transport mechanisms, as well as the creation of innovative functional materials with improved properties, is key challenges for further development of membrane engineering, and it requires further intensive research activities both at academic and industrial level. The progress on the design of improved membrane materials with tailored properties relies on the detailed study and probing of the structure at the atomic or mesoscopic scale, depending on the nature of the material and the requirements of the specific application that is targeted. In general, the development of a new advanced material can take $20+$ years from its initial discovery to the market. A method to booster the discovery and the deployment of advanced materials is to integrate simulations, experiments, and big data, as proposed by the Federal Government of the United States that launched the Materials Genome Initiative (MGI) in 2011. ${ }^{[37]}$ In particular, simulations are used to complement experiments in a range of conditions, under which experiments are hard to carry out, as well as to speed up the procedure of characterization of new materials with different formulations. Moreover, the rapid improvements in numerical simulation and modelling methods and algorithms together with the continuous increase in computer speed and increasingly improvements in supercomputer architectures opens perspectives for accelerating the research and development through contributing to the two interrelated axes of membrane improvements that are materials research and process design and optimisation. However, in order to achieve a complete description of structural, thermal, mechanical, and transport properties of membrane materials, simulations have to range across several characteristic length and time scales, starting from fundamental physical principles and experimental data. ${ }^{[38]}$

An important example of modelling activities refers gas separation. The key to success of membrane technology is materials with high gas permeability and high selectivity. However, there exists a permeability/selectivity trade-off, that is, materials with higher gas permeability often exhibit lower selectivity, and vice versa. ${ }^{[39]}$ One direction chosen by researches for producing high performance membranes for gas separations, has been the development of high free volume polymers with enhanced rigidity of the entire polymer structure. Microporous polymers, which have pores smaller than $2 \mathrm{~nm}$ in size, such as PIM materials ${ }^{[40,41]}$ and thermally rearranged (TR) polymers ${ }^{[42,43]}$ are efficient membrane materials and good candidates to overcome the well-known Robeson's upper bound limitation between permeability and selectivity.

Modelling activities have provided valuable insights toward the atomistic conformations and morphology of polymers. The role of backbone rigidity and bulky side groups and their ability to induce microporosity has been confirmed in many simulation studies, consistent with experimental works. ${ }^{[44-48]}$ Future de- 
velopments will require enhanced sorption of target gas pairs while maintaining the gas permeability due to their high free volume elements. Tuning the cavity size is quite essential for target gas pairs in order to increase membrane performance. ${ }^{[49]}$ Other examples on how to improve membrane performances is to prepare sorption-enhanced materials. ${ }^{[50,51]}$ Solubility selectivity is determined by the relative condensability of penetrants and their relative affinity toward membrane materials. Solubility selectivity has been extensively explored for $\mathrm{CO}_{2} /$ light gas separations by designing highly polar polymers with an affinity toward $\mathrm{CO}_{2}$ alone. As an example, the affinity, the miscibility and clusterization phenomena have been investigated in PEBAX block co-polymer membranes blended with the amphiphilic filler, $\mathrm{N}$-ethyl-o/p-toluenesulphonamide (KET). ${ }^{[52,53]}$ Modelling activities estimated the distribution and arrangements of modifiers into the matrix and related this to the macroscopic affinity behavior.

$M D$ simulations are extremely valuable also for improving the understanding of water treatment processes. Referring to desalination and water-reuse, simulations helped in elucidating some technological challenges, such as fouling of $\mathrm{RO}$ and NF membrane surfaces and the rejection of specific trace organic compounds that are dangerous for the environment or/and to human health. By creating membrane models in contact with water and salt solutions, useful information on the specific interaction between water and PA membrane and on the structure of confined water were attained. ${ }^{[54]}$ The selective polyamide layer of current RO membranes comprises an inhomogeneous tangled polymer network saturated by transmembrane "tunnels" and nanopores with a contorted contour and filled with water molecules changing in shape also at ambient temperatures. ${ }^{[55]}$

Referring to carbon nanotubes, the first simulation on water conduction through the hydrophobic channel by Hammer was performed in 2001. ${ }^{[56]}$ Since that time, simulations investigated water transport ${ }^{[57,58]}$ and ion conductivity, ${ }^{[15,59-61]}$ the factors governing the membrane embedding and pore permeability. ${ }^{[62,63]}$ Moreover, the variations of CNTs, e.g., in their diameter ${ }^{[59-61]}$ or by adding functional groups or modification of ends of $\mathrm{CNT}^{[64,65]}$ or in number of walls ${ }^{[66]}$ were also studied setting the foundation for a targeted design of CNT-membrane systems.

\section{Membrane Processes in Water Treatment}

Membrane technology was firstly commercialized in the 1960s and 1970s for various applications such as water filtration and pharmaceutical. Desalination by Reverse Osmosis (RO) entered the market only in the late 1960s when the membrane manufacturing process became efficient enough in producing desalted water and was competitive with thermal processes. Currently, the last projections indicate that the global membrane market is projected to reach USD 32.14 billion by 2020 from USD 18.68 billion in 2014, witnessing a CAGR (compound annual growth rate) of $9.47 \%$ between 2015 and 2020. The Asia-Pacific region dominated the membrane market in 2014 and accounted for $37.21 \%$ of the global market. This region dominates the membrane market due to the extensive usage of membranes in pharmaceutical \& medical use, water \& wastewater treatment, and chemical processing sectors. The Asia-Pacific region is expected to grow at the highest CAGR of $12.20 \%$ between 2015 and 2020 . The market for the Middle East Asian region is projected to witness the secondhighest CAGR of $10.40 \%$ between 2015 and 2020 owing to the increasing demand for water treatment plants in the region. Indeed, water treatment and production are the sectors that account for the majority of membrane application. According to
International Desalination Association (IDA) ${ }^{[67]}$ in the first half of 2015 , there were 18,426 desalination plants worldwide whilst 88.56 million $\mathrm{m}^{3} / \mathrm{d}$ was the global online capacity in the first half of 2016. Desalination is practiced in 150 different countries and it furnishes desalinated water to more than 300 million people. Regionally, the largest gains have been seen in the Middle East and North Africa, driven by several large-scale projects in multiple countries throughout the region, with demand outweighing the economic tolls of persistently low oil prices in several countries. In terms of technology, the general trend is the adoption of membrane over thermal technologies, and this becomes more acute from 2000 to 2016 (Figure 5).

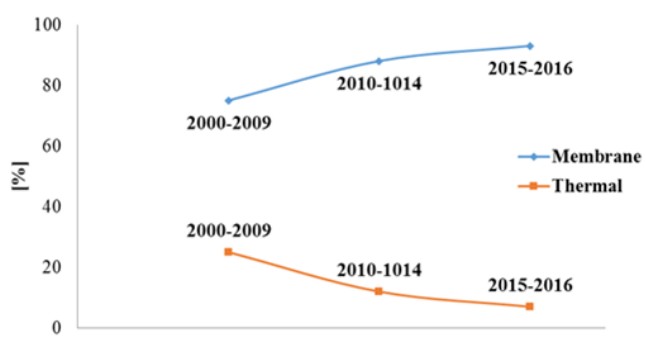

Figure 5 Global situation of time evolution of membrane vs. thermal desalination technologies.

The most common membrane-based desalination technologies are electrodialysis (ED) and reverse osmosis (RO). ED is a membrane process in commercial use for seawater or brackish water desalination since 1952. It is an electrically driven membrane operation non-economical for waters with high salt concentrations, ${ }^{[68,69]}$ rarely used for seawater desalination but competitive for brackish waters with up to 3,000 ppm salt concentrations. However, among the desalination technologies, reverse osmosis is the most widespread. ${ }^{[70,71]}$ The key to extensive implementation of seawater $\mathrm{RO}$ plants has been a significant reduction in capital and operation/maintenance costs over the past 30 years. Several factors have helped in reducing RO energy consumption and costs, including improvements in membrane materials and technology (higher flux, higher salt rejection, lower hydrostatic pressure required and lower materials cost) and the use of pressure recovery devices. RO has also become less expensive than thermal processes, which require an electricity consumption 10 times higher. ${ }^{[72,73]} \mathrm{RO}$ applications range from the production of ultrapure water for semiconductor and pharmaceutical use to the desalination of seawater for drinking water production and the purification of industrial wastewater. It is capable of rejecting nearly all colloidal or dissolved matter from an aqueous solution, producing a permeate stream, which consists of almost pure water (due to the high selectivity of the existing $\mathrm{RO}$ commercial membrane modules between $99.6 \%$ and $99.8 \%$ ). To date, all commercial RO membranes comprise polar or hydrophilic pores and only polymeric membranes have been employed for industrial use. Moreover, the most extensively used design in RO desalination is the spiral wound membrane module configuration (Figure 6d). The latter consists of consecutive layers of large membrane and support material in an envelope type design rolled up around a perforated steel tube. This design maximizes surface area in a minimum amount of space, contrarily to the first plate-and-frame type RO membrane modules of '60 (Figure 6a). ${ }^{[7]}$ Almost all the available commercial spiral wound membrane modules utilize thin-film composite membranes (Figure6c). These elements consist of three layers: a sublayer acting as structural support (120-150 mm thick), a microporous interlayer (about $40 \mathrm{~mm}$ ), and an ultra-thin barrier layer on theupper surface $(0.2 \mathrm{~mm})$. The support layer protects the 


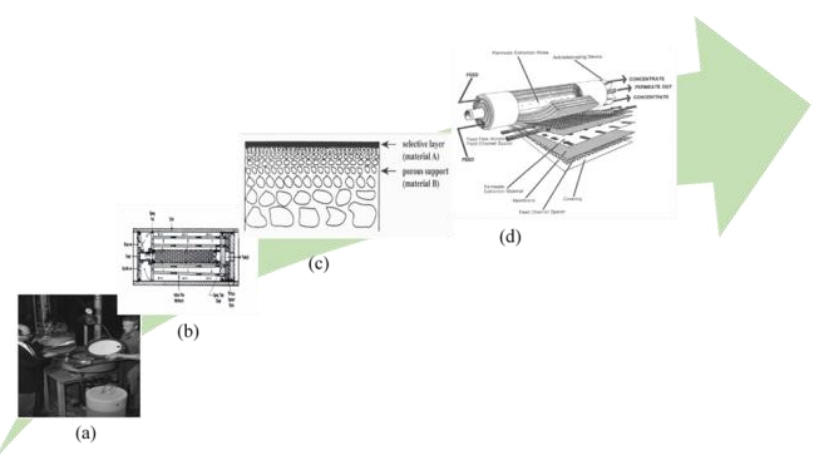

Figure 6 Time evolution of RO membranes and modules: (a) Prof. Sidney Loeb and engineer Ed Selover remove newly manufactured RO membrane from plate-and-frame production unit circa 1960; (b) Permasep Hollow Fiber B-10 Permeators from DuPont introduced commercially in Europe in 1974; (c) structure of a thin film composite (TFC) membrane constituting the most part of currently spiral wound membrane module RO configuration.

membrane from ripping or breaking, while the active layer is responsible for almost all resistance to mass transport and the selectivity of the membrane. Composite membranes can combine various materials and provide optimum properties depending on their use. The fabrication and performance of thin film composite membranes have been greatly improved in the past few decades. ${ }^{[75,76]}$ Thin-film composite membranes exhibit water permeability of around $3.5 \times 10^{-12} \cdot \mathrm{m}^{3} \cdot \mathrm{m}^{-2} \cdot \mathrm{Pa}^{-1} \cdot \mathrm{s}^{-1}$ and, as anticipated, can reject $99.6 \%$ to $99.8 \%$ of the salts dissolved in the seawater feed. ${ }^{[77]}$ Therefore, it is difficult to further increase the water permeability of these membranes without sacrificing rejection. ${ }^{[78,79]}$ This is a direct consequence of the separation mechanism of thin-film composite membranes, where increasing selectivity to allow higher removal of ions will substantially reduce the membrane permeability and will increase energy consumption. Developing $\mathrm{RO}$ membranes with higher rejection without sacrificing water permeability will necessitate a major paradigm shift, as it will require membranes that do not follow the solution-diffusion mechanism. Various nano-structured RO membranes have been proposed offering attractive characteristics and that could possibly bring revolutionary advancements (for example, the mixed matrix membranes, biomimetic RO membranes, graphene and graphene oxide, carbon nanotubes, ceramic/inorganic membranes, etc.). These membranes offer the possibility to fabricate new generations of RO membranes with permeability and rejection properties remarkably surpassing those of existing membranes. However, the development of such membranes is only in the initial stages and many problems are yet to be overcome, such as the high cost of nanostructured materials, the difficulty in scaling up of nano-membrane manufacturing processes, the control of concentration polarization and fouling phenomena, because the prevalent strategies for their management have already penalized the performance of current thin-film composite membrane and, therefore, have been inadequate for ultrahigh permeability membranes. Another shortcoming of TFC membranes is that their fabrication technique has not been successfully extended to hollow fiber configurations that offer higher packing densities (apart from the case of the Permasep Hollow Fiber B-10 Permeators from DuPont introduced commercially in Europe in 1974 (Figure 6b), and the HOLLOSEP®high-pressure type HL hollow fiber module from Toyobo recently commercialized).

In addition, the surface properties of thin-film composite membranes make them prone to fouling ${ }^{[57]}$ (i.e., Achilles's heel of pressure driven membrane process like $\mathrm{RO}$ ), which diminishes process performance. A possible solution is to develop new, thermally driven desalination (such as membrane distillation (MD) and membrane-assisted crystallization (MCr)) that are inherently less susceptible to fouling and concentration polarization phenomena compared to high-pressure membrane desalination methods. In MD, a hydrophobic membrane separates a hot (feed or retentate) and cold (distillate or permeate) stream of water. The temperature difference produces a vapour pressure gradient that causes water vapour to pass through the membrane. Only volatile components of the feed may be transported from the retentate to the permeate due to the hydrophobic nature of the membrane. The result is a distillate of very high purity that does not suffer from the entrainment of species which are non-volatile.

The water vapour condenses on the low-temperature side and pure water is formed. MD offers the attractiveness of operation at atmosphere pressure, theoretical ability to achieve $100 \%$ salts rejection, and low operation temperatures $\left(30-90^{\circ} \mathrm{C}\right.$ ) (with the additional advantage of utilizing waste heat or other sustainable energy resources). $\mathrm{MCr}$ is an extension of the MD concept. In this operation, the feed solution is concentrated to produce crystals and pure water from supersatured solutions. MD and $\mathrm{MCr}$ are both efficient tools for improving seawater desalination processes:

1. Integration of a MD unit to process RO retentate could (a) increase the amount of recovered water and (b) reduce the amount of discharged brine:

2. Integration of a MCr unit to process RO retentate could (a) enhance the water recovery factor, (b) minimize the discharged brine and (c) produce valuable crystalline products. ${ }^{[0-83,85]} \mathrm{De}-$ tails related to the characterization of the salts produced through $\mathrm{MCr}$ operation in the treatment of $\mathrm{NF} / \mathrm{RO}$ retentate streams as well as the analysis of the stability and control of $\mathrm{MCr}$ process can be found in references. ${ }^{[85,86]}$

In addition to membrane applications in seawater desalination, also in wastewater treatment and reuse membranes represent feasible solutions for the production of a sustainable alternative source of water. In this field, membrane bioreactor (MBR), a unit combining membrane filtration with biological treatment, is considered a Best Available Technology (BAT) for wastewater treatment and recycling due to its (i) decreased sludge production, (ii) higher and more consistent effluent quality, (iii) compactness (up to 5 times more compact than a conventional activated sludge plant). ${ }^{[68]}$

More recently, MBRs with MD membranes have been developed. The introduction of MDBR was due to the fact that, in a conventional MBR, the molecular weight cut-off of the utilized MF/UF membranes delivers a portion of the organic species of the feed. For overcoming this, high retention membrane bioreactors, such as membrane distillation MBR (MDBR), have been exploited for retaining, in principle, small size and persistent contaminants, which facilitates their biodegradation in the bioreactor, thereby producing higher quality product water. ${ }^{[86]}$ Other interesting integration of MD are with forward osmosis (FO), pressure retarded osmosis (PRO) and freeze desalination (FD). Forward osmosis (FO) is a membrane operation that can be used for removing dissolved components from water. FO exploits the osmotic pressure gradient across a semi-permeable membrane to promote a water flow from a feed solution into a draw concentrated solution. Then, the latter has to be treated (e.g., via MD) in order to remove the clean water and the draw solution that will be re-utilized. FO energy consumption is low because it requires only stirring or pumping of the solutions involved. ${ }^{[87,88]}$ The feasibility of a FO-MD hybrid system has been examined by concentrating solutions containing valuable industrial chemicals or pharmaceuticals. ${ }^{[89]}$ Wang 
et al. ${ }^{[90]}$ employed a bench-scale FO-MD hybrid system to treat highly viscous protein solution. In this FO-MD hybrid system, FO was employed for dewatering protein solutions, whereas MD was used for draw solution recovery. Another bench-scale FO-MD hybrid system was used to concentrate a dye solution, where the hybrid system efficiency was maximized by a balanced water flux of the FO and MD processes. ${ }^{[91]}$

$\mathrm{PRO}$ is a membrane technology that can be employed in the energy production stage. PRO utilizes the osmotic flow of water through semipermeable membranes from a low concentration solution into a high concentration solution to drive a hydro-turbine, thereby generating electricity. MD can be used for the regeneration of the low and high concentration solutions. ${ }^{\text {[92] }}$

In the recent years, freeze desalination (FD) has emerged as another possible desalination technology. Its main advantage is that fouling issues are mild and it requires only $1 / 7$ of the energy to freeze water than to vaporize it. FD drawback is that it is vulnerable to high feed concentrations. By contrast, MD is able to treat feed concentrations that are a few times higher than the seawater concentration without compromise on separation performance. The feasibility of an hybrid system consisting of freeze desalination and vacuum membrane distillation (FD-VMD) powered by waste energy and solar energy for seawater desalination was investigated by Chang et al. ${ }^{[93]}$ Their results indicate water recovery as high as $74 \%$.

Another innovative membrane assisted operation in the perspective of water separation and recovery from industrial waste gaseous steams is Membrane Condenser. ${ }^{[94-97]}$ In a membrane condenser, the waste gaseous stream from an industrial plant at a certain temperature and, in most cases, water saturated, is fed to the membrane condenser kept at a lower temperature for cooling the gas up to a super-saturation state. The water condenses onto the membrane surface and the hydrophobic nature of the latter prevents the penetration of the liquid into the pores, letting the dehydrated gases pass through the membrane and retaining the liquid water at the retentate side. In comparison with other technologies, the membrane condensers offer higher water recovery and are not affected by desiccant losses, corrosion phenomena typical of traditional condensers or desiccant units. Compared with the dense membrane technology, the latter requires a high-pressure difference between the two membrane sides to promote the permeation of water vapour, but allows the recovery of a very pure stream. Moreover, the possibility of controlling, by opportunely tuning the operating conditions, the condensation of contaminants in the liquid water recovered in the retentate side of the membrane condenser could lead to two different options for its use: as a unit for water recovery, minimizing the contaminants content, or as the pre-treatment stage in post-combustion capture, forcing most of the contaminants to be retained.

\section{Integrated Distillation-Pervaporation/Vapour Per- meation Systems}

On the other hand, a membrane can be coupled with a conventional distillation column, resulting in a hybrid membrane/distillation process. ${ }^{[98,99]}$ The combination of membrane processes like pervaporation and vapour permeation with distillation offers several advantages including reduction of energy consumption, improvement of product quality and avoidance of entrainers, making this technology especially suitable for close boiling or azeotropic mixtures. ${ }^{[100]}$ Most industrial applications have focused on the dehydration of solvents. Roza and Maus $^{[101]}$ reported possible significant energy savings of up to $50 \%$ compared to extractive and pressure swing distillation. It also leads to lower operating and investment costs. Fontalvo ${ }^{[102]}$ showed that total cost reductions of up to $60 \%$ are possible using a hybrid membrane distillation process for acetonitrile dehydration.

\section{Conclusions and Outlook}

The design and development of innovative membranebased integrated processes continue to increase, providing critical support for the future improvement of sustainable industrial growth.

The growing interest for new materials and, specifically, for inorganic materials with new interesting properties such as the graphene family, the $2 \mathrm{D}$ chalcogenides are receiving strategic interest for new membrane preparation. The specific characteristics of these materials in terms of thermal conductivity (very high or in some other case very low), the plasmonic phenomena inducing interesting surface properties, and the mixed matrix membranes filled with them are examples of new areas of immediate research to be addressed. These new membranes might be, as discussed, of particular importance for appropriate design of membrane and module for innovative new membrane assisted unit operations, such as membrane distillation, membrane crystallizer, membrane condenser, etc.

\section{Author Contributions}

The manuscript was written through contributions of all authors. All authors have given approval to the final version of the manuscript.

\section{References}

[1] Van Gerven, T.; Stankiewicz, A. Ind. Eng. Chem. Res. 2009, 48, 2465.

[2] http://eippcb.jrc.ec.europa.eu/reference/ (Last access on October 10, 2018).

[3] https://biomimicry.org/what-is-biomimicry/.

[4] http://eudime.unical.it/ (Last access on October 10, 2018).

[5] Adiga, S. P.; Jin, C.; Curtiss, L. A.; Monteiro-Riviere, N. A.; Narayan, R. J. Wiley Interdiscip. Rev. Nanomed. Nanobiotechnol. 2009, $1,568$.

[6] Wang, X.; Hsiao, B. S. Curr. Opin. Chem. Eng. 2016, 12, 62.

[7] Schiffman, J. D.; Schauer, C. L. Polym. Rev. 2008, 48, 317.

[8] Persano, L.; Camposeo, A.; Tekmen, C.; Pisignano, D. Macromol. Mater. Eng. 2013, 298, 504.

[9] Ahmed, F. E.; Lalia, B. S.; Hashaikeh, R. Desalination 2015, 356, 15.

[10] Capito, R. M.; Azevedo, H. S.; Velichko, Y. S.; Mata, A.; Stupp, S. I. Science 2008, 319, 1812.

[11] Li, J. H.; Xu, Y. Y.; Zhu, L. P.; Wang, J. H.; Du, C. H. J. Membr. Sci. 2009, 326, 659.

[12] Zhang, R.; Ji, S.; Wang, N.; Wang, L.; Zhang, G.; Li, J. R. Angew. Chem. Int. Ed. 2014, 53, 9775.

[13] Gugliuzza, A.; Aceto, M. C.; Macedonio, F.; Drioli, E. J. Phys. Chem. B 2008, 112, 10483.

[14] U.S. Patent No. 6800481

[15] Corry, B. J. Phys. Chem. B 2008, 112, 1427.

[16] Falk, K.; Sedlmeier, F.; Joly, L.; Netz, R. R.; Bocquet, L. Nano Lett. 2010, 10, 4067.

[17] Das, R.; Ali, M. E.; Hamid, S. B. A.; Ramakrishna, S.; Chowdhury, Z. Z. Desalination 2014, 336, 97

[18] Velleman, L.; Shapter, J. G.; Losic, D. J. Membr. Sci. 2009, 328, 121.

[19] Ward, T. J.; Baker, B. A. Anal. Chem. 2008, 80, 4363.

[20] Han, D.; Yan, L.; Chen, W.; Li, W. Carbohyd. Polym. 2011, 83, 653.

[21] Shin, M. K.; Lee, B.; Kim, S. H.; Lee, J. A.; Spinks, G. M.; Gambhir, S.; Kim, S. J. Nat. Commun. 2012, 3, 650.

[22] O'Hern, S. C.; Stewart, C. A.; Boutilier, M. S.; Idrobo, J. C.; 
Bhaviripudi, S.; Das, S. K.; Karnik, R. ACS Nano 2012, 6, 10130.

[23] O'Hern, S. C.; Boutilier, M. S.; Idrobo, J. C.; Song, Y.; Kong, J.; Laoui, T.; Karnik, R. Nano Lett. 2014, 14, 1234.

[24] Liu, R.; Arabale, G.; Kim, J.; Sun, K.; Lee, Y.; Ryu, C.; Lee, C. Carbon 2014, 77, 933

[25] Sun, P.; Zhu, M.; Wang, K.; Zhong, M.; Wei, J.; Wu, D.; Zhu, H. ACS Nano 2012, 7, 428.

[26] Sint, K.; Wang, B.; Král, P. J. Am. Chem. Soc. 2008, 130, 16448.

[27] Koenig, S. P.; Wang, L.; Pellegrino, J.; Bunch, J. S. Nat. Nanotechnol. 2012, 7, 728.

[28] Tang, C. Y.; Zhao, Y.; Wang, R.; Hélix-Nielsen, C.; Fane, A. G. Desalination 2013, 308, 34.

[29] Xia, F.; Wang, H.; Xiao, D.; Dubey, M.; Ramasubramaniam, A. Nat. Photonics 2014, 8, 899.

[30] Macedonio, F.; Politano, A.; Drioli, E.; Gugliuzza, A. Mater. Horiz. 2018, 5, 912.

[31] Liu, G.; Jin, W.; Xu, N. Angew. Chem. Int. Ed. 2016, 55, 13384.

[32] Zheng, Z.; Grünker, R.; Feng, X. Adv. Mater. 2016, 28, 6529.

[33] Gugliuzza, A.; Politano, A.; Drioli, E. Curr. Opin. Chem. Eng. 2017, 16, 78.

[34] Zuo, J.; Chung, T. S. Water 2016, 8, 586.

[35] Lu, K. J.; Zuo, J.; Chung, T. S. J. Membr. Sci. 2017, 539, 34.

[36] Liu, G.; Jin, W.; Xu, N. Angew. Chem. Int. Ed. 2016, 55, 2.

[37] White, A. MRS Bull. 2012, 37, 715.

[38] Laurini, E.; Fermeglia, M.; Pricl, S. In Engineering for the Treatment of Gases: Gas-Separation Issues with Membranes, Ed.: Drioli, E.; Barbieri, G.; Brunetti, A. The Royal Society of Chemistry, 2018, Vol. 1, p. 28.

[39] Robeson, L. B. J. Membr. Sci. 2008, 320, 390.

[40] McKeown, N. B.; Budd, P. M. Macromolecules 2010, 43, 5163.

[41] Budd, P. M.; Msayib, K. J.; Tattershall, C. E.; Ghanem, B. S.; Reynolds, K. J.; McKeown, N. B.; Fritsch, D. J. Membr. Sci. 2005, 251, 263.

[42] Park, H. B.; Jung, C. H.; Lee, Y. M.; Hill, A. J.; Pas, S. J.; Mudie, S. T.; Van Wagner, E.; Freeman, B. D.; Cookson, D. J. Science 2007, 318, 254.

[43] Park, H. B.; Han, S. H.; Jung, C. H.; Lee, Y. M.; Hill, A. J. J. Membr. Sci. 2010, 359, 11.

[44] Park, C. H.; Tocci, E.; Lee, Y. M.; Drioli, E. J. Phys. Chem. B 2012, 116, 12864.

[45] Park, C. H.; Tocci, E.; Kim, S.; Kumar, A.; Lee, Y. M.; Drioli, E. J. Phys. Chem. B 2014, 118, 2746.

[46] Tocci, E.; De Lorenzo, L.; Bernardo, P.; Clarizia, G.; Bazzarelli, F.; Mckeown, N. B.; Carta, M.; Malpass-Evans, R.; Friess, K.; Pilnáček, K.; Lanč, M.; Yampolskii, Y.. P.; Strarannikova, L.; Shantarovich, V.; Mauri, M.; Jansen, J. C. Macromolecules 2014, 47, 7900.

[47] Rogan, Y.; Malpass-Evans, R.; Carta, M.; Jansen, J. C.; Bernardo, P.; Clarizia, G.; Tocci, E.; Friess, K.; Lanc, M.; McKeown, N. B. J. Mater. Chem. A 2014, 2, 4874.

[48] Williams, R.; Esposito, E.; Jansen, J. C.; Tocci, E.; Rizzuto, C.; Lanč, M.; Carta, M.; McKeown N.il. B. J. Mater. Chem. A 2018, 6, 5661.

[49] Kupgan, G.; Abbott, L. J.; Hart, K. E.; Colina, C. M. Chem. Rev. 2018, 118, 5488.

[50] Omidva, M.; Nguyen, H.; Liu, J.; Lin, H. Curr. Opin. Chem. Eng. 2018, 20, 50 .

[51] Jiang, X.; Li, S.; He, S.; Bai, Y.; Shao, L. J. Mater. Chem. A 2018, 6, 15064.

[52] De Lorenzo, L.; Tocci, E.; Gugliuzza, A.; Drioli, E. J. Membr. Sci. 2012, 412-422, 75

[53] De Lorenzo, L.; Tocci, E.; Gugliuzza, A.; Drioli, E. Membranes 2012, 2, 346.

[54] Shen, M.; Keten, S.; Lueptow, R. M. J. Membr. Sci. 2016, 506, 95.

[55] Ridgway, H. F.; Orbell, J.; Gray, S. J. Membr. Sci. 2017, 524, 436.

[56] Hummer, G.; Rasaiah, J. C.; Noworyta, J. P. Nature 2001, 414, 188.

[57] Whitby, M.; Quirke, N. Nat. Nanotechnol. 2007, 2, 87.
[58] Joseph, S.; Aluru, N. R. Nano Lett. 2008, 8, 452.

[59] Beckstein, O.; Tai, K.; Sansom, M. S. J. Am. Chem. Soc. 2004, 126, 14694.

[60] Peter, C.; Hummer, G. Biophys. J. 2005, 89, 2222.

[61] García-Fandiño, R.; Sansom, M. S. P. Proc. Natl. Acad. Sci. U. S. A. 2012, 109, 6939.

[62] Wallace, E. J.; Sansom, M. S. P. Nano Lett. 2008, 8, 2751.

[63] Chan, W. F.; Chen, H. Y.; Surapathi, A.; Taylor, M. G.; Shao, X. H.; Marand, E.; Johnson, J. K. ACS Nano 2013, 7, 5308.

[64] Corry, B. Energy Environ. Sci. 2011, 4, 751.

[65] Hughes, Z. E.; Shearer, C. J.; Shapter, J.; Gale, J. D. J. Phys. Chem. C 2012, 116, 24943.

[66] Rizzuto, C.; Pugliese, G.; Bahattab, M. A.; Aljlil, S. A.; Drioli, E.; Tocci, E. Sep. Purif. Technol. 2018, 193, 378

[67] http://idadesal.org/desalination-101/desalination-by-the-numbers/.

[68] Brunetti, A.; Macedonio, F.; Barbieri, G.; Drioli, E. Environ. Eng. Res. 2015, 20, 307.

[69] Van der Bruggen, B.; Vandecasteele, C. Desalination 2002, 143, 207.

[70] IDA Desalination Yearbook. Media Analytics Ltd., United Kingdom, 2017-2018.

[71] IDA Desalination Yearbook. Media Analytics Ltd., United Kingdom, 2016-2017.

[72] Bernardo, P.; Drioli, E. Petrol. Chem. 2010, 50, 271.

[73] Koros, W. J. J. Membr. Sci. 2007, 300, 1.

[74] http://archive.li/IEDuN (original source: http://www.engineer.ucla. edu/history/osmosis.ht ml).

[75] Elimelech, M.; Phillip, W. A. Science 2011, 333, 712

[76] Lee, K. P.; Arnot, T. C.; Mattia, D. J. Membr. Sci. 2011, 370, 1.

[77] Busch, M.; Mickols, W. E. Desalination 2004, 165, 299.

[78] Macedonio, F.; Enrico, E. Engineering 2017, 3, 290.

[79] Geise, G. M.; Park, H. B.; Sagle, A. C.; Freeman, B. D.; McGrath, J. E. J. Membr. Sci. 2011, 369, 130.

[80] Macedonio, F.; Curcio, E.; Drioli, E. Desalination 2007, 203, 260

[81] Macedonio, F.; Drioli, E. Desalination 2008, 223, 396.

[82] Macedonio, F.; Drioli, E.; Curcio, E.; Di Profio, G. Desalin. Water Treat. 2009, 9, 49.

[83] Macedonio, F.; Drioli, E. Desalin. Water Treat. 2010, 18, 224.

[84] Macedonio, F.; Katzir, L.; Geisma, N.; Simone, S.; Drioli, E.; Gilron, J. Desalination 2011, 273, 127.

[85] Drioli, E.; Curcio, E.; Criscuoli, A.; Di Profio, G. J. Membr. Sci. 2004, 239, 27.

[86] Drioli, E.; Macedonio, F. Ind. Eng. Chem. Res. 2012, 51, 10051.

[87] Macedonio, F.; Drioli, E.; Gusev, A. A.; Bardow, A.; Semiat, R.; Kurihara, M. Chem. Eng. Process. 2012, 51, 2.

[88] Macedonio, F.; Drioli, E. Engineering 2017, 3, 290.

[89] Xie, M.; Nghiem, L. D.; Price, W. E.: Elimelech, M. Environ. Sci. Technol. 2013, 47, 13486.

[90] Wang, K. Y.; Teoh, M. M.; Nugroho, A.; Chung, T.-S. Chem. Eng. Sci. 2011, 66, 2421.

[91] Ge, Q.; Wang, P.; Wan, C.; Chung, T.-S. Environ. Sci. Technol. 2012, 46, 6236.

[92] Lin, S.; Yip, N. Y.; Cath, T. Y.; Osuji, C. O.; Elimelech, M. Environ. Sci. Technol. 2014, 48, 5306.

[93] Chang, J.; Zuo, J.; Lu, K. J.; Chung, T. S. Desalination 2019, 449, 16.

[94] Macedonio, F.; Brunetti, A.; Barbieri, G.; Drioli, E. Ind. Eng. Chem. Res. 2013, 52, 1160.

[95] Drioli, E.; Santoro, S.; Simone, S.; Barbieri, G.; Brunetti, A.; Macedonio, F.; Figoli, A. React. Funct. Polym. 2014, 79, 1.

[96] Brunetti, A.; Santoro, S.; Macedonio, F.; Figoli, A.; Drioli, E.; Barbieri, G. Clean-Soil, Air, Water 2014, 42, 1145.

[97] Macedonio, F.; Brunetti, A.; Barbieri, G.; Drioli, E. Sep. Purif. Technol. 2017, 181, 60.

[98] Moganti, S.; Noble, R. D.; Koval, C. A. J. Membr. Sci. 1994, 93, 31.

[99] Stephan, W.; Noble, R. D.; Koval, C. A. J. Membr. Sci. 1995, 99, 259. 


\section{Minireview}

[100] Lipnizki, F.; Field, R. W.; Ten, P.-K. J. Membr. Sci. 1999, 153, 183.

[101] Roza, M.; Maus, E. In Proceedings of the International Conference on Distillation \& Absorption, London, 2006, p. 619.

[102] Fontalvo, J.; Cuellar, P.; Timmer, J. M. K.; Vorstman, M. A. G.; Wijers, J. G.; Keurentjes, J. T. F. Ind. Eng. Chem. Res. 2005, 44,
5259.

Received October 17, 2018 Accepted November 27, 2018 